\title{
Master's Degree, a New Requirement to Become an RDN by 2024: A Comparison of Nutrition Graduate Programs Offered in the USA
}

\author{
Monica Sanchez, Deanna L. Pucciarelli \\ Department of Nutrition and Health Science, Ball State University, Muncie, IN, USA \\ Email: mnsanchez2@bsu.edu,dpucciarelli@bsu.edu
}

How to cite this paper: Sanchez, M. and Pucciarelli, D.L. (2019) Master's Degree, a New Requirement to Become an RDN by 2024: A Comparison of Nutrition Graduate Programs Offered in the USA. Food and Nutrition Sciences, 10, 1-14.

https://doi.org/10.4236/fns.2019.101001

Received: November 29, 2018

Accepted: December 30, 2018

Published: January 2, 2019

Copyright (๑) 2019 by authors and Scientific Research Publishing Inc. This work is licensed under the Creative Commons Attribution International License (CC BY 4.0).

http://creativecommons.org/licenses/by/4.0/ (c) (i) Open Access

\begin{abstract}
Background: The registered dietetic four-year degree educational structure has been intact since 1926. Master level nutrition programs exist in the U.S., but are not standardized or accredited unlike four-year degrees. Academic requirements for nutrition graduate programs vary regionally across the nation. Objective: To 1) quantify and describe the availability of Master level nutrition programs regionally; and 2) examine the current M.A. and M.S. program requirements for a nutrition graduate degree in the U.S. Methods: Nutrition graduate programs $(\mathrm{n}=201)$ were analyzed and compared by geographical region. Data were collected between August 2017 and May 2018. Inclusion criteria were defined as: nutrition graduate programs listed in the American Society of Nutrition (ASN) database that had a nutrition graduate program website. Descriptive statistical analysis measured evaluated variables. Results: A total of 201 nutrition graduate programs in the U.S. were identified. The title of the programs was categorized into 29 main themes. The most common nutrition graduate program title was a M.S. in Nutrition, 55 institutions (27.4\%). A total of 181 institutions offered a M.S. with a required thesis, whereas 95 offered a M.S. with a non-thesis option, and only eight offered a M.A. Region 3-South offered the highest number of nutrition graduate programs (66), followed by region 2-Midwest with 49 programs, region 1-Northeast offered a total of 46 programs, and 37 programs were offered in region 4-West. Conclusion: In 2024, as part of the RD eligibility criteria, it will be required that students possess a master's degree. To date, only one master's program in the U.S. is accredited, which assures the student a measure of confidence of program rigor and accountability. Dietitians' three major professional concerns: respect, recognition and rewards are predicated
\end{abstract}


on rigorous educational programs that meet ACEND standards. It is unlikely that all U.S. master level programs will be accredited by 2024 .

\section{Keywords}

Nutrition Graduate Program Requirements, Graduate Program Curriculum Rigor, Registered Dietitian Nutritionist Credential (RDN), RDN

Requirements, Accreditation

\section{Introduction}

In response to economic, technical and medical practice changes, a college level education degree is now expected when hiring healthcare professionals. Dating back to its inception, the field of dietetics required an advanced degree [1]. Although competencies and knowledge requirements within the degree have evolved in response to changing medical paradigms and purposes, the registered dietetic four-year degree educational structure has been intact. In 1926, the then-titled American Dietetic Association required all members to receive a four-year college degree plus six months of hospital training. At that time only medical doctors and dietitians required four-year college degrees [2].

In 2005, the Dietetic Education Task Force noted that "defining the profession through education and credentialing standards is one of the few true levers available for change" [3]. The Council on Future Practice (CFP) works in collaboration with the Commission on Dietetic Registration (CDR), Accreditation Council for Education in Nutrition and Dietetics (ACEND) and Nutrition and Dietetics Educators and Preceptors (NDEP) to ensure viability and relevance of the nutrition and dietetics profession [4]. In 2012, in conjunction with the CFP and input from ACEND, CDR, and the Education Committee, nine recommendations were developed and published in a document titled: Visioning Report (VR). Recommendations that have an impact on graduate level education included: "Elevate the educational preparation for the future entry-level Registered Dietitian (RD) to a minimum of a graduate degree from an ACEND-accredited program", and "...require an ACEND-accredited graduate degree program and/or consortium that integrates both the academic coursework and supervised practice components into a seamless (1-step) program as a requirement to obtain the future entry-level RD credential" [3]. To date, however, ACEND-accredited graduate degree programs in the U.S. are limited to a single program.

The VR emphasized that over decades, the Academy of Nutrition and Dietetics (Academy) has updated content, curriculum, competencies and programs, but the undergraduate structure of education has remained the same. As a consequence, the ACEND Standards Committee developed new standards and competencies for a new model of education in nutrition and dietetics with the purpose of advancing the profession and protecting the public, which resulted in the Future Education Model (FEM) [5]. The FEM updated accreditation standards 
for associate and bachelor degree programs which were released in February 2017. In addition, FEM developed accreditation standards for graduate programs, which are restricted to early adopter demonstration programs [6].

In April 2018, ACEND released a Standards Update report, which announced that the Academy accredited Rutgers University Master of Science in Clinical Nutrition program as a demonstration program under the FEM accreditation standards for graduate degree programs [7]. Thus, Rutgers University Master of Science in Clinical Nutrition program became the first and, so far, only program to be accredited under the Future Graduate (FG) accreditation standards in the U.S. [7] [8]. The benchmark year, 2024, is fast approaching and to date only one graduate program has been awarded accreditation.

Over the past two decades, assessments conducted on practicing dietitians and report findings demonstrate a repeating pattern of concerns. The 2008 Needs Assessment report, which included 6955 participants (Academy members and CDR credentialed practitioners), outlined the most common challenges facing the dietetics field: recognition of the value delivered to the larger society (77\%), public awareness of the field (75\%), reimbursement for services (74\%) and compensation (74\%). Dietitians continue to express concern on three main areas: respect, recognition, and rewards (also known as the three R's) [3] [9]. To mitigate these concerns the Academy is raising the educational credential required for all new RDs.

The VR provides direction for preparing students in the future and is not intended to impact current practitioners [3]. To meet the increased demand for Masters level credentialed RDs, programs must be available to incoming students seeking the credential in addition to current RDs practicing in the field who may want to adopt the new standards to stay competitive. Master level nutrition programs exist in the U.S., but are not standardized or accredited by the Academy unlike four-year degrees. Some programs offer a Master of Arts (M.A.) degree while other programs offer Master of Science (M.S.) degree. Within the M.S. credential there are programs that require a thesis to be written while increasingly more programs require additional classroom-based education credits, better known as a M.S. with non-thesis option. If one of the goals for the advanced degree is to increase respect for $\mathrm{RD}$ practitioners, will other medical professionals and the general public accept or value the varying, non-standardized degree options? Classically within the sciences a M.S. required a research project that cumulated in a thesis, whereas this study will demonstrate the nutrition academic field is moving towards a non-thesis option. Most students seek educational programs where they reside; regionally, are there enough nutrition programs available for new and existing RDs who may be interested in completing an advanced degree?

The main objectives of this study were to: 1) quantify and describe the availability of Master level nutrition programs regionally; and 2) examine the current M.A. and M.S. program requirements for a nutrition graduate degree in the U.S. 


\section{Methods}

\subsection{Data Collection}

Data were collected between August 2017 and May 2018. Graduate nutrition programs were identified through the Graduate Program Directory listed by the American Society for Nutrition (ASN) [10]. All programs listed in the ASN were sourced, which included a total of 152 nutrition graduate programs. An additional 49 nutrition graduate programs were found through the Study Portals Masters website (https://www.mastersportal.com/) [11], and included in the sample. Supplementary resources included; the Applicant Guide to Supervised Practice 2016-2017, which was used as a cross-reference for a list of current dietetic internships (DI) offered in the U.S., where DIs and graduate programs are paired. The Academy of Nutrition and Dietetics website [12], was used as an additional source to cross-check DI programs that result in a graduate degree. Academy member self-reported RD/RDN credential and advanced degree credential (M.A., M.S., PhD) counts were collected from the Academy statistician (Roxanne Way Carter, email communication, June 1, 2018).

Inclusion criteria were defined as: nutrition graduate programs with a nutrition graduate program website, which provided an overview of their program with details on program requirements. A total of 206 graduate nutrition programs were originally included in the dataset. Institutions that lacked a nutrition graduate program website even though they were listed in the ASN directory were excluded $(n=5)$. A total of 201 nutrition graduate programs were reviewed. Data were analyzed by geographical region as defined by the U.S. Census Bureau [13].

\subsection{Statistical Analysis}

Descriptive statistical analysis tabulated the following variables: name and location of institution, name of the program, research institute category, distance (on campus, on-line or mix program), average time to complete the program, M.A. offered and credit hours, M.S. with thesis offered and credit hours, M.S. with non-thesis offered and credit hours, tracks offered and credit hours, comprehensive examination required, DI or Individualized Supervised Practice Pathway (ISPP) linked to a graduate degree. Program and DI credit hours and tuition for in-state and out-state students were analyzed by mean and standard deviation. Data were analyzed using Statistical Package for the Social Sciences (SPSS) v.24 for Windows (SPSS, 2017).

\section{Results}

A total 201 nutrition graduate programs in the U.S. were identified. The program titles were categorized into 29 themed programs. Frequencies indicated that the most common nutrition graduate program offered in the U.S. was a M.S. in Nutrition, 55 (27.4\%), followed by a M.S. in Nutritional Science, 26 (12.9\%), M.S. in Food and Nutrition, 13 (6.5\%), Coordinated Master's in Nutri- 
tion and Dietetics, 12 (6.0\%); and, a M.S. in Human Nutrition, 10 (5.0\%). Only eight institutions (4.0\%) offered a M.S. in Nutrition and Dietetics. A M.S. in Food Science as a concentration, a M.S. in Food and Nutrition and Human Sciences, and M.S. in Nutrition and Health Sciences was observed in 8 institutions (4.0\%) respectively; whereas, M.S. in Clinical Nutrition was offered in 6 (3.0\%), likewise 6 institutions (3.0\%) offered a M.S. in Food Science and Human Nutrition, and Public Health in Nutrition. A M.S. in Exercise and Nutrition Science was listed by 5 institutions $(2.5 \%)$.

Geographical location (Table 1) of nutrition graduate programs offered in the U.S. indicated that Region 1-Northeast, division 1: New England, offered a total of 17 programs with Massachusetts leading the region with 9 institutions (52.9\%), compared to Region 1-Northeast, division 2: Mid-Atlantic, which had a higher number of total institutions, 29, with New York having the majority of institutions, 18 (62.1\%). A total of 33 institutions offered a nutrition graduate program within Region 2-Midwest, division 3: East North Central. Illinois maintains the highest number of institutions in this region (14 institutions, or 42.4\%). In comparison, region 2-Midwest, division 4: West North Central had almost half the nutrition graduate programs offered with a total of 16 institutions. Missouri led this division with a total of 5 institutions (31.3\%). Region 3-South is divided in 3 main divisions; division 5: South Atlantic, division 6: East South Central, and division 7: West South Central. A total of 33 institutions offered a nutrition graduate program within division 5: South Atlantic. The majority of the programs were found in North Carolina (7 institutions or 21.2\%). Division 6: East South Central, had a total of 14 programs. This region was led by Alabama with 6 institutions (42.9\%). Division 7: West South Central indicated a slightly higher number of programs when compared to division 6. A total of 19 programs were found within this division. Texas had the majority of programs with a total of 12 institutions (63.2\%). Two main divisions were considered part of region 4-West. A total of 14 programs were found in Division 8: Mountain, in which Utah had the majority of programs with a total of 3 institutions $(21.4 \%)$. A higher number of programs were observed in region 4-West in the last division 9: Pacific. A total of 26 nutrition graduate programs were found in this region. Aligned with its population size, California had the highest number of programs within the division, with a total of 14 institutions (53.8\%).

Type of master's program offered was analyzed. A total of 181 institutions noted that they offered a M.S. with a required thesis, whereas 95 institutions listed that they offered a M.S. with a non-thesis option, and only eight institutions offered a M.A. (Figure 1). A total of 56 programs offered a DI paired graduate degree.

A total of 121 institutions indicated the average time to complete their nutrition graduate program (M.S. with thesis, M.S. with non-thesis, and M.A.). The mean average time to complete a program was $2.03 \pm 0.30$ years. The majority of institutions $105(86.8 \%)$ indicated 2.0 years as their average time for completion. 
Table 1. Nutrition graduate programs offered by region and division in the U.S.

\begin{tabular}{|c|c|c|}
\hline \multicolumn{3}{|c|}{ Region 1-Northeast: Division 1: New England } \\
\hline State & $\begin{array}{l}\text { Institution Frequency } \\
\text { (n) }\end{array}$ & $\begin{array}{l}\text { Percent } \\
(\%)\end{array}$ \\
\hline Connecticut & 4 & 23.5 \\
\hline Maine & 1 & 5.9 \\
\hline Massachusetts & 9 & 52.9 \\
\hline New Hampshire & 1 & 5.9 \\
\hline Rhode Island & 1 & 5.9 \\
\hline Vermont & 1 & 5.9 \\
\hline Total & 17 & 100.0 \\
\hline \multicolumn{3}{|c|}{ Region 1-Northeast: Division 2: Mid-Atlantic } \\
\hline New Jersey & 3 & 10.3 \\
\hline New York & 18 & 62.1 \\
\hline Pennsylvania & 8 & 27.6 \\
\hline Total & 29 & 100.0 \\
\hline \multicolumn{3}{|c|}{ Region 2-Midwest: Division 3: East North Central } \\
\hline Illinois & 14 & 42.4 \\
\hline Indiana & 4 & 12.1 \\
\hline Michigan & 8 & 24.2 \\
\hline Ohio & 5 & 15.2 \\
\hline Wisconsin & 2 & 6.1 \\
\hline Total & 33 & 100.0 \\
\hline \multicolumn{3}{|c|}{ Region 2-Midwest: Division 4: West North Central } \\
\hline Iowa & 2 & 12.5 \\
\hline Kansas & 2 & 12.5 \\
\hline Minnesota & 1 & 6.3 \\
\hline Missouri & 5 & 31.3 \\
\hline Nebraska & 4 & 25.0 \\
\hline North Dakota & 1 & 6.3 \\
\hline South Dakota & 1 & 6.3 \\
\hline Total & 16 & 100.0 \\
\hline \multicolumn{3}{|c|}{ Region 3-South: Division 5: South Atlantic } \\
\hline Delaware & 1 & 3.0 \\
\hline Florida & 5 & 15.2 \\
\hline Georgia & 5 & 15.2 \\
\hline Maryland & 3 & 9.1 \\
\hline North Carolina & 7 & 21.2 \\
\hline South Carolina & 2 & 6.1 \\
\hline Virginia & 5 & 15.2 \\
\hline Washington, D.C. & 3 & 9.1 \\
\hline West Virginia & 2 & 6.1 \\
\hline Total & 33 & 100.0 \\
\hline
\end{tabular}




\begin{tabular}{|c|c|c|}
\hline \multicolumn{3}{|c|}{ Region 3-South: Division 6: East South Central } \\
\hline Alabama & 6 & 42.9 \\
\hline Kentucky & 2 & 14.3 \\
\hline Mississippi & 3 & 21.4 \\
\hline Tennessee & 3 & 21.4 \\
\hline Total & 14 & 100.0 \\
\hline \multicolumn{3}{|c|}{ Region 3-South: Division 7: West South Central } \\
\hline Arkansas & 2 & 10.5 \\
\hline Louisiana & 2 & 10.5 \\
\hline Oklahoma & 3 & 15.8 \\
\hline Texas & 12 & 63.2 \\
\hline Total & 19 & 100.0 \\
\hline \multicolumn{3}{|c|}{ Region 4-West: Division 8: Mountain } \\
\hline Arizona & 2 & 14.3 \\
\hline Colorado & 2 & 14.3 \\
\hline Idaho & 1 & 7.1 \\
\hline Montana & 1 & 7.1 \\
\hline Nevada & 1 & 7.1 \\
\hline New Mexico & 2 & 14.3 \\
\hline Utah & 3 & 21.4 \\
\hline Wyoming & 2 & 14.3 \\
\hline Total & 14 & 100.0 \\
\hline \multicolumn{3}{|c|}{ Region 4-West: Division 9: Pacific } \\
\hline California & 14 & 53.8 \\
\hline Hawaii & 1 & 3.8 \\
\hline Oregon & 5 & 19.2 \\
\hline Washington & 6 & 23.1 \\
\hline Total & 26 & 100.0 \\
\hline
\end{tabular}

Only 6 schools (4.9\%) indicated a shorter average time to complete the nutrition graduate program, with 1 year listed as the average time.

Mean credit hours for the M.A. degree was $33.40 \pm 3.58$. In comparison, the average credit hours for a M.S. with thesis was slightly higher with a mean of $34.95 \pm 7.67$ credit hours. Pursuing a M.S. with a non-thesis option required the highest mean credit hours $35.00 \pm 6.47$.

Cross tabulations between types of nutrition graduate program and geographical location (Figure 2) indicated that Region 1-Northeast, Region 2-Midwest, and Region 3-South offered three, four, and one out of the eight M.A. programs, respectively. When M.S. with non-thesis option programs were compared, distribution of programs varied among regions (Chi-Square X2 = $8.016 ; \mathrm{df}=3$; $\mathrm{p}$-value $=0.046$ ). The majority of programs that required a thesis 


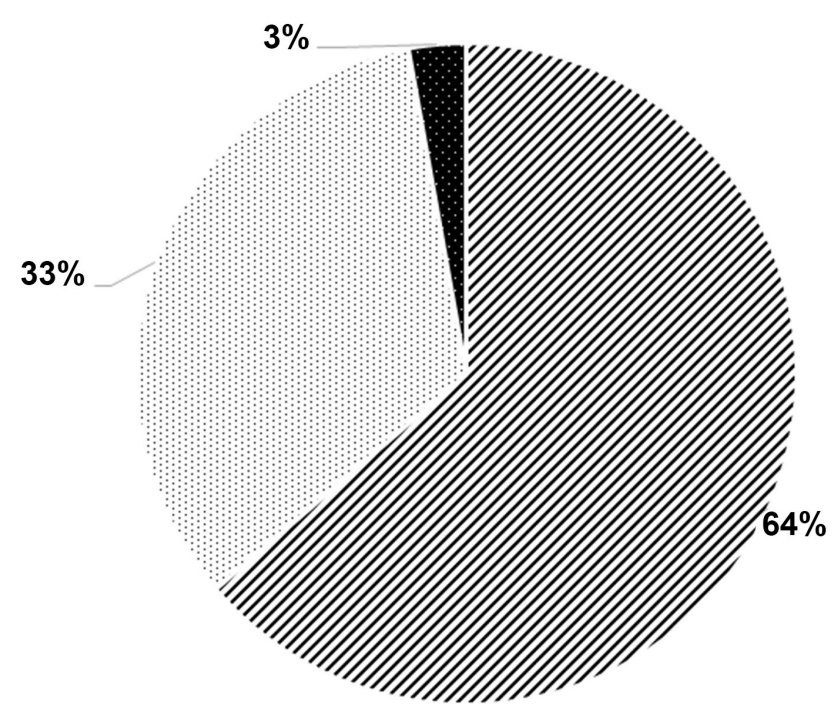

\%.S. with thesis

M.S. with non-thesis option

M.A. option

Figure 1. Type of program offered by institution; M.S. with thesis, versus M.S. with non-thesis option and M.A. $(n=201)$.

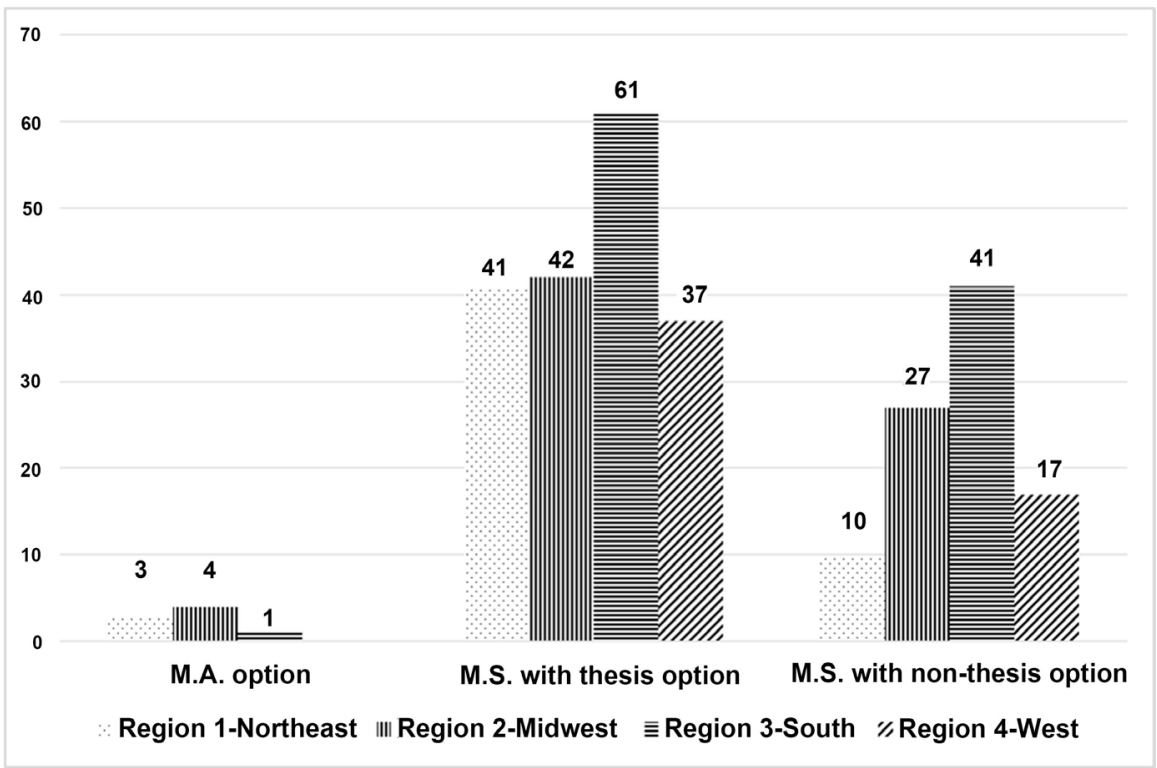

Figure 2. Geographic regions in the U.S. and type of nutrition graduate program offered by institution $\left(X^{2}=8.016\right.$; $\mathrm{df}=3$; $\mathrm{p}$-value $\left.=0.046\right)$.

were found in Region 3-South with a total of 61 institutions, followed by Region 2-Midwest, Region 1-Northeast and Region 4-West with 42, 41 and 37 institutions, respectively. The distribution of a M.S. non-thesis option by region again showed that Region 3-South had the greatest concentration of institutions with a total of 41 institutions. The region with the second highest concentration of M.S. 
with non-thesis option programs was Region 2-Midwest, with a total of 27 institutions, followed by Region 4-West with 17 institutions. Region 1-Northeast showed the lowest number of institutions offering a M.S. non-thesis option with only 10 institutions.

The total number of RDNs in the U.S. was compared with the total number of RDNs holding a master's degree or any other advanced degree (Table 2). Results indicated that in Region 3-South: Division 5-South Atlantic there was a higher number of RDNs holding an advanced degree (6268), followed by Region 1-Northeast: Division 2-Mid-Atlantic (5226); Region 4-West: Division 9-Pacific (5112); Region 2-Midwest: Division 3-East North Central (4857); Region 3-South: Division 7-West South Central (3865); Region 1-Northeast: Division 1-New England (2283); Region 4-West: Division 8-Mountain (2253); Region 2-Midwest: Division 4-West North Central (2212); and Region 3-South: Division 6-East South Central (1959).

\section{Discussion}

The new requirement to earning the $\mathrm{RD}$ credential has been changed by the CDR from a baccalaureate degree to a minimum of a master's degree beginning in 2024. Currently, in the U.S., as of May 2018, the CDR reported a total of 99,893 RDs and Registered Dietitian Nutritionists (RDN) [14]. In addition to students entering the nutrition and dietetic discipline, to stay competitive in the field, many RDs practitioners will consider obtaining an advanced degree.

Future students considering the $\mathrm{RD}$ career path may question, while investigating educational requirements, will there be enough graduate nutrition programs to fulfil student demand (regionally or otherwise), and will the programs be standardized and meet accreditation requirements set forth by the Academy? The results in this study identified 201 nutrition graduate programs in the U.S., and only one program, Rutgers University Master of Science in Clinical Nutrition program, has been accredited under the FG accreditation standards.

An important factor to consider is availability of nutrition programs offered in the U.S. in a student's geographic region. We found that region 3-South offers the highest number of nutrition graduate programs (66), followed by region 2-Midwest with 49 programs, region 2-Northeast offers a total of 46 programs, and 37 programs were offered in region 4 -West.

Differences between master's program requirements can be a factor when students evaluate which graduate program to pursue. The majority of programs offered a M.S. with a thesis requirement $(\mathrm{n}=181)$, whereas 95 institutions listed a M.S. with a non-thesis option (some institutions offered both), and only eight institutions offered a M.A. Similarly, time to program completion can influence program choice. The majority of institutions $105(86.8 \%)$ indicated 2.0 years as their average time. Only 6 schools $(4.9 \%)$ indicated a shorter average time to complete the nutrition graduate program, with 1 year listed as the average time. One of the nine recommendations by the VR is "to require an ACEND-accredited graduate program that integrates both the academic coursework and supervised 
Table 2. Comparison of self-reported Registered Dietitian Nutritionist (RDN) with an advanced degree by regions ${ }^{1}$.

\begin{tabular}{|c|c|c|c|}
\hline \multicolumn{4}{|c|}{ Region 1-Northeast: Division 1: New England } \\
\hline State & $\begin{array}{l}\text { Advance Degree } \\
\text { Frequency } \\
\text { (n) }\end{array}$ & $\begin{array}{c}\text { Total RDNs by } \\
\text { State } \\
\text { Frequency } \\
\text { (n) }\end{array}$ & $\begin{array}{c}\text { Comparison } \\
\text { Percentage } \\
(\%)\end{array}$ \\
\hline Connecticut & 507 & 1430 & 35.45 \\
\hline Maine & 198 & 428 & 46.26 \\
\hline Massachusetts & 1151 & 2821 & 40.80 \\
\hline New Hampshire & 175 & 586 & 29.86 \\
\hline Rhode Island & 147 & 396 & 37.12 \\
\hline Vermont & 105 & 246 & 42.68 \\
\hline Total & 2283 & 5907 & 38.65 \\
\hline \multicolumn{4}{|c|}{ Region 1-Northeast: Division 2: Mid-Atlantic } \\
\hline New Jersey & 1036 & 2946 & 35.17 \\
\hline New York & 2712 & 6803 & 39.86 \\
\hline Pennsylvania & 1478 & 4555 & 32.45 \\
\hline Total & 5226 & 14304 & 36.54 \\
\hline \multicolumn{4}{|c|}{ Region 2-Midwest: Division 3: East North Central } \\
\hline Illinois & 1537 & 4156 & 36.98 \\
\hline Indiana & 562 & 2010 & 27.96 \\
\hline Michigan & 884 & 3349 & 26.40 \\
\hline Ohio & 1274 & 4411 & 28.88 \\
\hline Wisconsin & 600 & 2238 & 26.81 \\
\hline Total & 4857 & 16164 & 30.05 \\
\hline \multicolumn{4}{|c|}{ Region 2-Midwest: Division 4: West North Central } \\
\hline Iowa & 233 & 1073 & 21.71 \\
\hline Kansas & 309 & 988 & 31.28 \\
\hline Minnesota & 612 & 2378 & 25.74 \\
\hline Missouri & 610 & 1963 & 31.07 \\
\hline Nebraska & 277 & 749 & 36.98 \\
\hline North Dakota & 71 & 399 & 17.79 \\
\hline South Dakota & 100 & 303 & 33.00 \\
\hline Total & 2212 & 7853 & 28.17 \\
\hline \multicolumn{4}{|c|}{ Region 3-South: Division 5: South Atlantic } \\
\hline Delaware & 107 & 298 & 35.91 \\
\hline Florida & 1610 & 4885 & 32.96 \\
\hline Georgia & 877 & 2405 & 36.47 \\
\hline
\end{tabular}




\section{Continued}

\begin{tabular}{|c|c|c|c|}
\hline Maryland & 740 & 1843 & 40.15 \\
\hline North Carolina & 1390 & 3236 & 42.95 \\
\hline South Carolina & 422 & 1182 & 35.70 \\
\hline Virginia & 869 & 2348 & 37.01 \\
\hline Washington, D.C. & 103 & 240 & 42.92 \\
\hline West Virginia & 150 & 358 & 41.90 \\
\hline Total & 6268 & 16795 & 37.32 \\
\hline \multicolumn{4}{|c|}{ Region 3-South: Division 6: East South Central } \\
\hline Alabama & 494 & 1338 & 36.92 \\
\hline Kentucky & 417 & 1329 & 31.38 \\
\hline Mississippi & 280 & 793 & 35.31 \\
\hline Tennessee & 768 & 2067 & 37.16 \\
\hline Total & 1959 & 5527 & 35.44 \\
\hline \multicolumn{4}{|c|}{ Region 3-South: Division 7: West South Central } \\
\hline Arkansas & 382 & 832 & 45.91 \\
\hline Louisiana & 469 & 1374 & 34.13 \\
\hline Oklahoma & 478 & 1110 & 43.06 \\
\hline Texas & 2536 & 6770 & 37.46 \\
\hline Total & 3865 & 10086 & 38.32 \\
\hline \multicolumn{4}{|c|}{ Region 4-West: Division 8: Mountain } \\
\hline Arizona & 588 & 1753 & 33.54 \\
\hline Colorado & 766 & 2306 & 33.22 \\
\hline Idaho & 142 & 634 & 22.40 \\
\hline Montana & 98 & 387 & 25.32 \\
\hline Nevada & 157 & 568 & 27.64 \\
\hline New Mexico & 183 & 443 & 41.31 \\
\hline Utah & 279 & 1010 & 27.62 \\
\hline Wyoming & 40 & 147 & 27.21 \\
\hline Total & 2253 & 7248 & 31.08 \\
\hline \multicolumn{4}{|c|}{ Region 4-West: Division 9: Pacific } \\
\hline Alaska & 73 & 222 & 32.88 \\
\hline California & 3669 & 10598 & 34.62 \\
\hline Hawaii & 136 & 409 & 33.25 \\
\hline Oregon & 381 & 1178 & 32.34 \\
\hline Washington & 853 & 2524 & 33.80 \\
\hline Total & 5112 & 14931 & 34.24 \\
\hline
\end{tabular}

${ }^{1} \mathrm{MA}, \mathrm{MS}$ and $\mathrm{PhD}$, combined; data retrieved May 30, 2018. 
practice components into a seamless (1-step) program" [3]. Nationally, 56 programs offered this option [12].

Accreditation is a means to ensure quality and standards to an external audience, and ACEND monitors and ensures undergraduate nutrition and dietetic education. Program accreditation directly relates to two of the three R's (respect and recognition) RDs reported as important to their career. Prior studies reported that academic quality was the top purpose to accreditation [15]. Future students and current RDs will search for graduate programs that are accredited by ACEND, and program differences (M.S. thesis vs non-thesis) will need to be standardized for quality and rigor.

As the nutrition and dietetics field prepares to adopt and implement new credentialing standards it is important to determine if these upcoming benchmarks can be reached given the current availability of institutional programming and lack of standardization. In addition to the new RD credential requirement, current $\mathrm{RDs}$ may be interested in obtaining an advanced degree. Region 1-Northeast: Division 1-New England (Table 2) has the highest percentage (38.65\%) of RDs with self-reported advanced degrees while Region 2 Midwest: Division 4-West North Central has the lowest (28.17\%). Interest from current $\mathrm{RDs}$ in enrolling in advanced degrees programs coupled with the new $\mathrm{RD}$ advance degree requirement in these regions may increase demand. Interest may exceed capacity. For example, North Dakota has one graduate program (Table 1), and only $17.79 \%$ (Table 2) of current RDs report having an advanced degree. Institutions that offer on-line only advanced degree options will have an advantage and will attract students nationally. The Academy may want to encourage institutions to build advance degree options that can be delivered $100 \%$ on-line, or very limited on-campus coursework requirements.

On-line only advanced degrees lend themselves to $100 \%$ coursework M.S. degrees in contrast to M.S. degree programs that require the thesis option. The consequence may be that more RDs will have less exposure to thesis engaged advanced degrees. How this will affect the research skillset from the pool of applicants for doctoral programs remains to be determined.

A limitation in the study design is that the ASN database was the only data source for graduate program requirements offered in the United States. It is conceivable that other nutrition graduate programs exist. Likewise, the Academy's Applicant Guide to Supervised Practice 2016-2017, which was used as a cross-reference for a list of current dietetic internships (DI) offered paired with a graduate degree may not represent all paired programs. The researchers identified only a single accredited nutrition graduate program and more may exist. Currently, an archive of accredited graduate programs is not available on the Internet. A follow-up study to record changes will need to be completed before 2024.

\section{Conclusion}

In 2024 , as part of the $\mathrm{RD}$ eligibility criteria, it will be required that students 
possess a master's degree. Thus, those students pursuing a DI without a linked graduate program would have to complete a nutrition graduate program or any other master's program to be eligible for credentialing. Certain regions have nutrition graduate programs to meet the new demand while other regions would be unable to meet the demand. To ensure rigor and standardization across programs criteria must be completed, tested and evaluated prior to 2024. Accreditation ensures a level of expectation and outcome to an external audience. The three main areas of concern in dietetics remains: respect, recognition, and rewards. Would those entry-level dietitians with a master's degree in 2024 see any improvements in the field? Currently in the U.S. nutrition graduate programs have varying requirements to earn the degree. It will be important that a measure of standardization across programs be developed and oversight committees monitor program quality to protect the value of the degree.

\section{Acknowledgements}

We would like to express our gratitude for the contributions from James Jones, $\mathrm{PhD}$, Research and Academic Effectiveness Director, Ball State University for his assistance with the data analysis. We would like to thank Mrs. Roxanne Way Carter and the Commission on Dietetic Registration for providing the RNDs self-report, advanced degree data.

\section{Conflicts of Interest}

The authors declare no conflicts of interest regarding the publication of this paper.

\section{References}

[1] Hwalla, N. and Koleilat, M. (2004) Dietetic Practice: The Past, Present and Future. Eastern Mediterranean Health Journal, 10, 716-730.

[2] Academy of Nutrition and Dietetics Foundation (2017) The History of the Academy of Nutrition and Dietetics. https://eatrightfoundation.org/who-we-are/academy-history-timeline/

[3] Academy of Nutrition and Dietetics (AND) (2012) Visioning Report: Moving Forward-A Vision for the Continuum of Dietetics Education, Credentialing and Practice. https://www.cdrnet.org/pub/file.cfm?item_type $=x m \_f i l e \& i d=10369$

[4] Academy of Nutrition and Dietetics (AND) (2018) Council on Future Practice. https://www.eatrightpro.org/leadership/committees-and-task-forces/listing/councilon-future-practice

[5] Academy of Nutrition and Dietetics (AND) (2018) Future Education Model. https://www.eatrightpro.org/acend/accreditation-standards-fees-and-policies/future -education-model

[6] Academy of Nutrition and Dietetics (AND) (2018) ACEND Mission and Vision. https://www.eatrightpro.org/acend/about-acend/acend-mission-and-vision

[7] Accreditation Council for Education in Nutrition and Dietetics (ACEND) (2018) Standards Update: April 2018 Formative and Summative Assessments.

[8] Accreditation Council for Education in Nutrition and Dietetics (ACEND) (2017) Accreditation Standards for Graduate Degree Programs in Nutrition and Dietetics 
(FG): Future Education Model.

[9] Rogers, D. (2009) Report on the American Dietetic Association/Commission on Dietetic Registration 2008 Needs Assessment. Journal of the American Dietetic Association, 109, 1283-1293. https://doi.org/10.1016/j.jada.2009.05.022

[10] American Society for Nutrition (ASN) (2017) Graduate Program Directory. https://nutrition.org/meetings/graduate-program-directory/

[11] Study Portals Masters. Masters in Nutrition and Dietetics. https://www.mastersportal.com/

[12] Academy of Nutrition and Dietetics (AND) (2018) Dietetic Internships. https://www.eatrightpro.org/acend/accredited-programs/dietetic-internships

[13] United States Census Bureau (2018) Geographic Terms and Concepts: Census Divisions and Census Regions.

https://www2.census.gov/geo/pdfs/maps-data/maps/reference/us_regdiv.pdf

[14] Commission on Dietetic Registration (CDR) (2018) Registry Statistics. https://www.cdrnet.org/registry-statistics

[15] Pucciarelli, D.L., Hall, S.S. and Harden, A. (2016) Quality, Accountability, and Improvement: A National Survey of Perceived Value of AAFCS Accreditation. Family and Consumer Sciences Research Journal, 44, 375-393.

https://doi.org/10.1111/fcsr.12170 